\title{
Cloning and Characterization of a Novel Invertase from the Obligate Biotroph Uromyces fabae and Analysis of Expression Patterns of Host and Pathogen Invertases in the Course of Infection
}

\author{
Ralf T. Voegele, ${ }^{1}$ Stefan Wirsel, ${ }^{2}$ Ulla Möll, ${ }^{1}$ Melanie Lechner, ${ }^{1}$ and Kurt Mendgen ${ }^{1}$ \\ ${ }^{1}$ Phytopathologie, Fachbereich Biologie, Universität Konstanz, 78457 Konstanz, Germany; ${ }^{2}$ Institut für Pflanzenzüchtung \\ und Pflanzenschutz, Martin-Luther-Universität Halle-Wittenberg, 06099 Halle (Saale), Germany
}

Submitted 22 November 2005. Accepted 6 February 2006.

\begin{abstract}
Invertases are key enzymes in carbon partitioning in higher plants. They gain additional importance in the distribution of carbohydrates in the event of wounding or pathogen attack. Although many researchers have found an increase in invertase activity upon infection, only a few studies were able to determine whether the source of this activity was host or parasite. This article analyzes the role of invertases involved in the biotrophic interaction of the rust fungus Uromyces fabae and its host plant, Vicia faba. We have identified a fungal gene, $U f$-INV1, with homology to invertases and assessed its contribution to pathogenesis. Expression analysis indicated that transcription began upon penetration of the fungus into the leaf, with high expression levels in haustoria. Heterologous expression of Uf-INV1 in Saccharomyces cerevisiae and Pichia pastoris allowed a biochemical characterization of the enzymatic activity associated with the secreted gene product INV1p. Expression analysis of the known vacuolar and cell-wallbound invertase isoforms of $V . f a b a$ indicated a decrease in the expression of a vacuolar invertase, whereas one cellwall-associated invertase exhibited increased expression. These changes were not confined to the infected tissue, and effects also were observed in remote plant organs, such as roots. These findings hint at systemic effects of pathogen infection. Our results support the hypothesis that pathogen infection establishes new sinks which compete with physiological sink organs.
\end{abstract}

Additional keywords: sink marker.

Invertases ( $\beta$-D-fructofuranoside fructohydrolase [EC 3.2.1.26]) are enzymes widely distributed among bacteria, fungi, and plants (Yanai et al. 2001). They catalyze the hydrolysis of terminal nonreducing $\beta$-D-fructofuranoside residues in $\beta$-D-fructofuranosides, with sucrose being the major substrate (Myrbäck 1960). The disaccharide sucrose is the major long-distance transport form for assimilates in higher plants (Weber and Roitsch 2000). Therefore, sucrose-cleaving enzymes, such as invertases, play a pivotal role in carbon partitioning in these organisms (Sturm 1999).

Plants contain different isoforms of invertases, which can be distinguished by their subcellular localization, $\mathrm{pH}$ optimum,

Corresponding author: R. T. Voegele; Telephone: +49 7531 884305; Fax: +49 7531 883035; E-mail: Ralf.Voegele@uni-konstanz.de and isoelectric point (Godt and Roitsch 1997). Neutral or alkaline invertases are localized in the cytoplasm (Roitsch and Gonzalez 2004). Little is known about the function of these isoforms, but they are believed to be involved in sucrose catabolism (Sturm and Tang 1999). Soluble acid invertases are localized in the vacuole and are thought to be responsible for regulating the extent to which sucrose accumulates during photosynthesis and to determine the amount of sucrose available for export (Scholes et al. 1996). The best-studied invertase isoforms are the insoluble acid invertases located in the apoplastic space (Tymowska-Lalanne and Kreis 1998). They are typically Nglycosylated and the polypeptides carry a net positive charge which is responsible for binding to acidic components of the cell wall (Ramloch-Lorenz et al. 1993). Acid invertases are characterized by the presence of two sequence motives (Goetz and Roitsch 1999, 2000). The NDPN box, also designated the $\beta$-fructosidase motif, seems to play a major role in catalysis. The WEC-P/V-D sequence distinguishes soluble vacuolar (V) and insoluble apoplastic $(\mathrm{P})$ isoforms. Insoluble acid invertases are thought to be the key players in the determination of sink strength of storage organs through apoplastic phloem unloading (Eschrich 1989; Weber et al. 1995). Moreover, either directly or indirectly through altering sugar ratios, these enzymes also play a major role in the regulation of developmental processes (Heyer et al. 2004; Weschke et al. 2003).

Fungal invertases are well studied at the biochemical level, especially the enzymes from Saccharomyces cerevisiae and several Aspergillus spp., the latter mainly because of the capability of some invertases to produce fructooligosaccharides at a technical scale (Boddy et al. 1993; Heyer and Wendenburg 2001; Neumann and Lampen 1967; Yanai et al. 2001). Although the biochemical characteristics are not fundamentally different from the plant enzymes, the DNA sequences indicate a separate evolution of fungal invertases.

The similar kinetic parameters make it difficult to discern the contributions of plant and fungal enzymes when both organisms occur together (e.g., in mutualistic symbiosis or obligate biotrophic parasitism). There are a number of publications indicating an increase in invertase activity as a response to biotic stress stimuli (Benhamou et al. 1991; Fotopoulos et al. 2003; Heisterüber et al. 1994; Tang et al. 1996; Wright et al. 1995). However, for most of the systems analyzed, it has not been possible to distinguish the contribution of plant or fungus to the observed invertase activity increase (Billett et al. 1977; Callow et al. 1980; Krishnan and Pueppke 1988; Williams et al. 1984). Only for the necrotrophic parasite Botrytis cinerea 
has it been possible to show a contribution of the fungus to the invertase increase during infection of Vitis vinifera (Ruffner et al. 1992; Ruiz and Ruffner 2002).

We set out to analyze the source and roles of invertases in the biotrophic interaction of the rust fungus Uromyces fabae with its host plant Vicia faba. We have identified a gene with homology to invertases in U. fabae, cloned the gene, and characterized the gene product using heterologous expression. The gene is expressed during parasitic growth and the gene product catalyses the irreversible breakdown of sucrose into D-glucose and D-fructose. We also have assessed the influence the infection with $U$. fabae has on the expression of the three known $V$. faba invertases. Our results indicate that rises in host invertase expression as well as a fungal sucrolytic activity contribute to the overall increase in invertase activity in this pathosystem.

\section{RESULTS}

\section{Isolation of Uf-INV1.}

Screening a haustorium-specific $U$. fabae cDNA library for sequences with similarity to known $\beta$-D-fructofuranoside fructohydrolases, we identified a partial clone with homology to Aspergillus niger invertase (AAC08047) (Boddy et al. 1993). A polymerase chain reaction (PCR) fragment of this partial cDNA clone was used to screen cDNA and genomic libraries. A genomic clone was obtained and sequenced by primer walking using PCR fragments as templates. All positive cDNA clones identified were of the same size as the original partial clone or smaller. Therefore, the full-length cDNA was generated by nested PCR using uncloned cDNA prepared from haustoria as template and introducing unique restriction sites in the nested PCR step. Sequence data for $U f-I N V I$ have been deposited at the EMBL database under the accession number AJ640083.

Of the $3.6 \mathrm{~kb}$ of sequence determined from the genomic DNA, 746 and 54 bp composed 5' and $3^{\prime}$ noncoding sequences, respectively. Comparison of the cDNA sequence with that of the genomic clone revealed the presence of seven introns, ranging in size from 61 to $87 \mathrm{bp}$ (average $75 \mathrm{bp}$ ). The translational start site was found to reside at position 747 of the genomic sequence. The size of the $5^{\prime}$ untranslated region could not be determined because of the PCR approach. The $3^{\prime}$ untranslated region present in the partial cDNA clones comprised $54 \mathrm{bp}$. The cDNA contained an open reading frame of 2,265 bp, coding for a polypeptide of 754 amino acids (aa) with a predicted molecular weight of $84.3 \mathrm{kDa}$. This value exceeds the figures reported for most other invertases. Of the 155 entries currently in the BRENDA database, only 2 sequences code for larger polypeptides.

An in silico analysis for potential localization signals (Bendtsen et al. 2004) gave evidence for a potential secretion signal and indicated an extracellular localization of the gene product. Prediction of the signal peptide cleavage site suggested a 25-aa signal peptide and S26 as the N-terminal amino acid of the mature protein $\left(\mathrm{M}_{1}\right.$ CYSTSKSFVSLLCAAVLSSG $\left.\mathrm{SISA}_{25} / \mathrm{S}_{26}\right)$. The calculated molecular mass of the mature polypeptide is $81.8 \mathrm{kDa}$.

BLASTP searches revealed highest similarity to invertases from Aspergillus spp. (S33920, AAC08047, BAB67771, and $\mathrm{CAB} 89083)$ and hypothetical proteins from a number of fungal genome-sequencing projects (Gibberella zeae [XP_388591 and XP_383464], Magnaporthe grisea [EAA52657 and

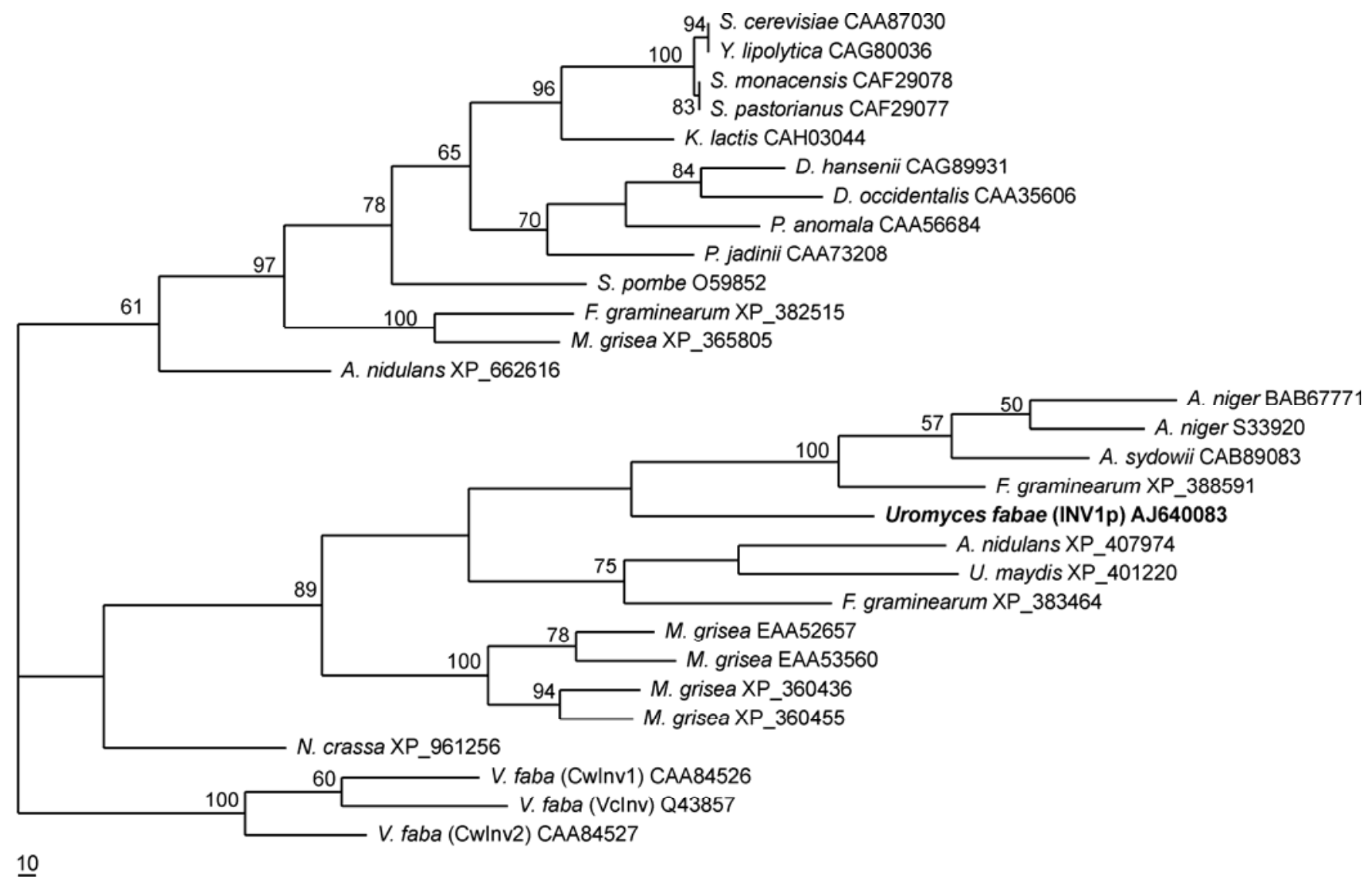

Fig. 1. Phylogenetic analysis of INV1p. Molecular phylogeny showing the relationship of INV1p, corresponding database matches found by BlastP, and three invertases from Vicia faba, which were used as outgroup. Sequences are designated by name of organism and accession number. The depicted tree was obtained by parsimony analysis based on a total of 29 sequences and 349 informative characters. Bootstrap support values of more than $50 \%$ are indicated. 
EAA53560], and Ustilago maydis [XP_401220]). Much lower scores were obtained for bacterial invertases, inulinases (EC 3.2.1.7), and levanases (EC 3.2.1.65). Similarity to plant invertases was low and confined to the $\mathrm{N}$-terminus of the protein. Phylogenetic analyses indicate that INV1p and related fungal sequences form a separate clade (Fig. 1). The NDPN box (Goetz and Roitsch 2000), also known as the $\beta$-fructosidase motif, is realized only as an NDP box in INV1p and related fungal invertases. The second signature sequence typical for all plant invertases, the WEC-P/V-D box (Goetz and Roitsch 2000), discriminating between vacuolar (V) and cell-wallbound $(\mathrm{P})$ isoforms, could not be identified in INV1p or any of the homologous fungal sequences.

In order to identify the copy number of $U f-I N V 1$, a Southern blot carrying genomic DNA isolated from uredospores and digested with several restriction enzymes was hybridized with a digoxygenin-labeled $U f$-INVI cDNA fragment (Fig. 2). Our results, together with the sequence uniformity of all the analyzed partial $U f-I N V 1$ cDNA clones (data not shown), indicate that $U f-I N V I$ is present as a single copy in the genome.

\section{Expression pattern of $\boldsymbol{U f - I N V I \text { . }}$}

The expression of $U f-I N V I$ during rust development was analyzed by Northern hybridization. Onset of $U f-I N V I$ expression coincided with the penetration of the fungus into the leaf (Fig. 3). Expression was very high in haustoria, but the signal obtained for infected leaves had approximately the same intensity. The ratio between the haustorial and the infected leaf samples together with the early onset of transcription indicates that $U f-I N V 1$ is not a typical in planta-expressed gene $(P I G)$. These $P I G$ s are exclusively or at least preferentially expressed in haustoria (Hahn and Mendgen 1997).

In order to confirm this result and to analyze the expression pattern of $U f-I N V 1$ at a better resolution, we analyzed $U f-I N V I$ with a more sensitive reverse-transcriptase (RT)-PCR approach (Wirsel et al. 2001). Transcripts were analyzed in infected plants of various stages ( 1 to 18 days postinfection [dpi]), in vitrodifferentiated infection structures ( 2 to $26 \mathrm{~h}$ postinfection [hpi]), and liquid culture (Fig. 4). The latter arrested uredospore differentiation in the germ tube stage and, therefore, made it possible to check for a morphogenic control. Uf-PMA1, encoding a plasma membrane ATPase, served as an internal control for constitutive expression (Wirsel et al. 2001). Uf-PMAl expression was almost constant in all in vitro structures tested and in

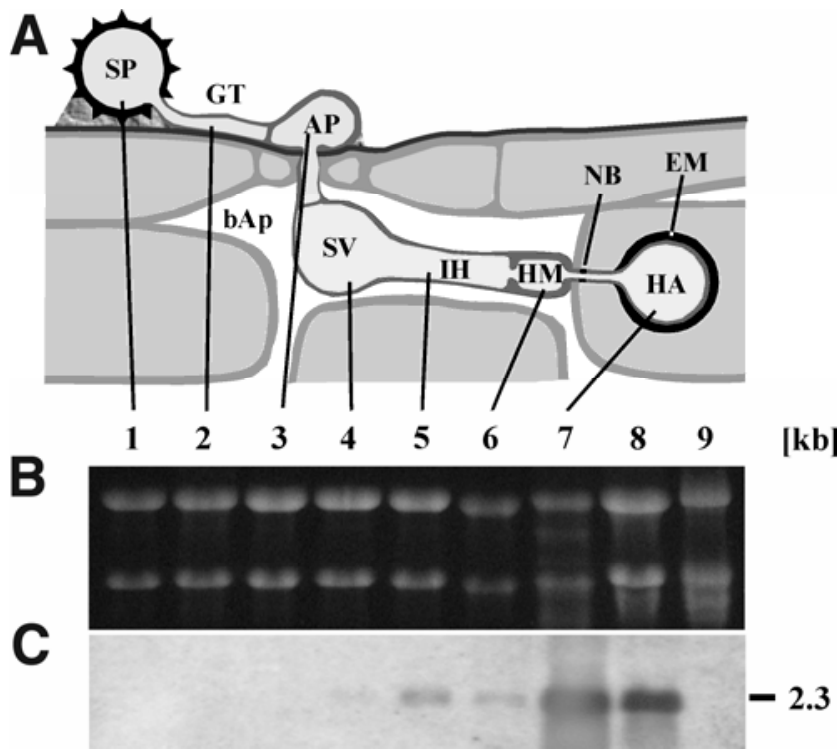

Fig. 3. $U f-I N V 1$ is not an in planta-induced gene $(P I G)$. A, Schematic representation of rust infection structures. B, Ethidium bromide-stained denaturing agarose gel (loading control). C, Northern blot of the gel depicted in B. Lane 1, uredospore (SP); lane 2, germ tube (GT) after $4 \mathrm{~h}$ of germination; lanes 3 to 6 , in vitro infection structures harvested at the following stages: 3, appressorium (AP) stage $(6 \mathrm{~h}) ; 4$, substomatal vesicle (SV) stage $(12 \mathrm{~h}) ; 5$, infection hyphae (IH) stage (18 h); 6 , haustorial mother cell (HM) stage (21 h); lane 7, isolated haustoria (HA); lane 8, infected leaves at 7 days postinfection; lane 9, noninfected leaves; bAp, bulk apoplast; $\mathrm{NB}$, neckband; EM, extrahaustorial matrix. The number on the right gives the size estimated in kilobases.

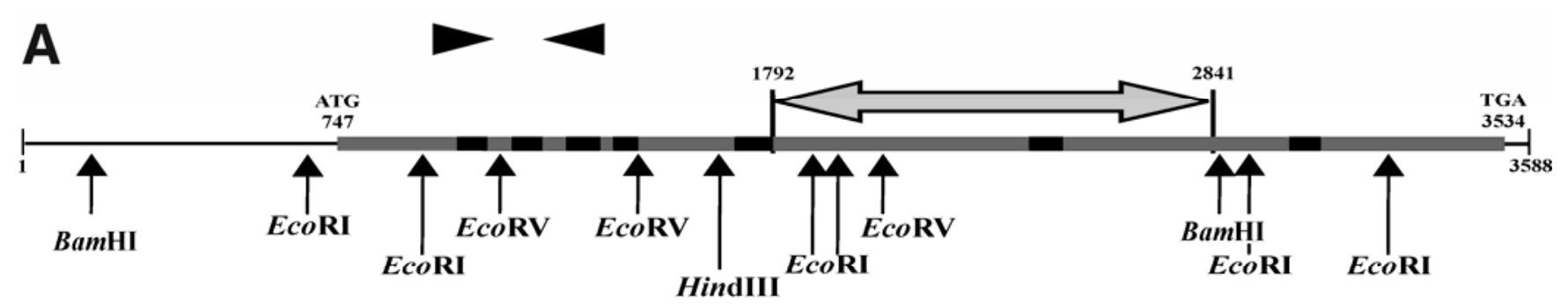

B

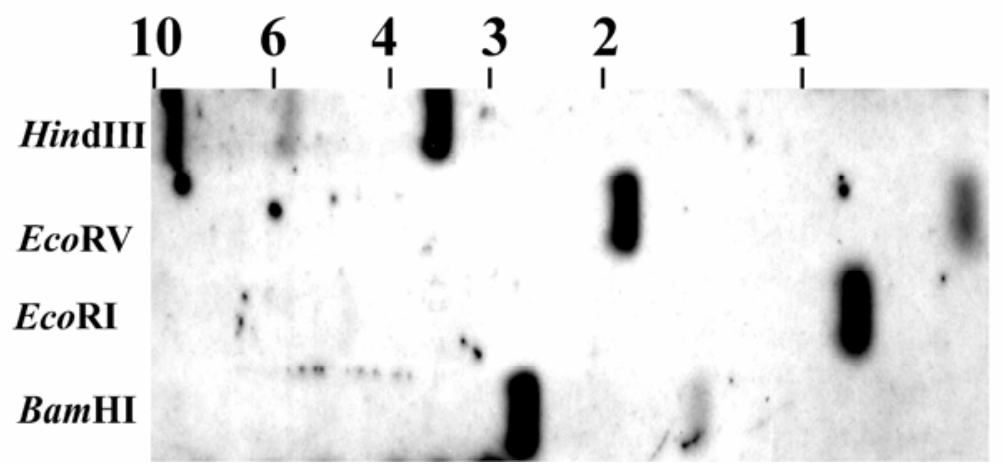

Fig. 2. $U f-I N V 1$ is a single-copy gene. A, Schematic representation of the Uf-INVI sequence. The position of cleavage sites for restriction enzymes and the position of the probe used for hybridization are indicated. Dark boxes specify intron positions and the horizontal arrows highlight the positions of the primers used for reverse-transcriptase polymerase chain reaction. B, Total DNA of Uromyces fabae was prepared from germinated spores and digested with: HindIII, EcoRV, EcoRI, and BamHI. Numbers on top give the size of the molecular weight marker in kilobases. 
liquid culture. For the in planta samples, transcription could be detected starting with day eight after infection. Uf-INVI expression was detectable in liquid culture and in in vitro-grown infection structures, rising from barely detectable in spores to a substantial amount in 26-h-old structures. Strong expression was seen in infected leaves $8 \mathrm{dpi}$, but faint bands were visible from the first day after infection. This result confirms our findings from Northern analyses that $U f-I N V I$ is not a haustorium-specific gene. $U f-I N V 1$ seems to be expressed at substantial levels soon after penetration of the fungus into the leaf and throughout the intercellular hyphae.

\section{Localization of the gene product INV1p.}

In order to determine whether INV1p is indeed an extracellular enzyme and to ascertain its exact localization, we raised and purified two sets of polyclonal antibodies. Superimposed phase contrast and fluorescence images depicting a haustorium inside a mesophyll cell and an intercellular hypha are shown in Figure 5. Labeling with S698p (and S755p; data not shown) resulted in strong fluorescence signals only in the periphery of haustoria. Controls with pre-immune sera did not result in any labeling. The observed signals are consistent with a secretion of INV1p. However, although $U f-I N V 1 \mathrm{mRNA}$ could be detected in haustoria and intercellular hyphae (Fig. 3), no fungal or plant structures other than haustoria were labeled using either antibody.

Both sets of antibodies also were effective in Western blot analysis. No signal was obtained for uninfected leaves, while specific cross-reactions at approximately $118 \mathrm{kDa}$ were clearly visible for infected leaves and haustorial samples (Fig. 6A). Treatment of the INV1p-containing samples using endoglycosidase $\mathrm{H}_{\mathrm{f}}$ resulted in a shift of the cross-reacting band to approximately $85 \mathrm{kDa}$. This is in good agreement with the molecular mass predicted for the mature polypeptide and provided further evidence for an extracellular localization of INV1p.

\section{Heterologous expression of $\boldsymbol{U} \boldsymbol{f}-\mathbf{I N V} \boldsymbol{V}$.}

In order to characterize the gene product biochemically, we subcloned the complete open reading frame, including its putative secretion signal, into the $S$. cerevisiae expression vector pDR195. Transformants of strain SEY2102 carrying either the vector pDR195 or plasmid pDR195::INV1 showed no differ- ence in growth on SC medium with glucose as carbon source (Sherman 1991); however, on SC medium with sucrose as sole carbon source, only plasmid pDR195::INV1 was able to complement the invertase negative phenotype of this strain (data not shown). This was the first direct evidence that INV1p truly acts as an invertase (EC 3.2.1.26). However, INV1p always remained tightly associated with the cells, as indicated by Western blotting (Fig. 6B) and activity assays (data not shown). Therefore, we used a second expression system, Pichia pastoris, which has been reported to be superior for the expression of secreted proteins. For secretion of INV1p in this system, the native signal sequence was replaced by the alpha factor signal

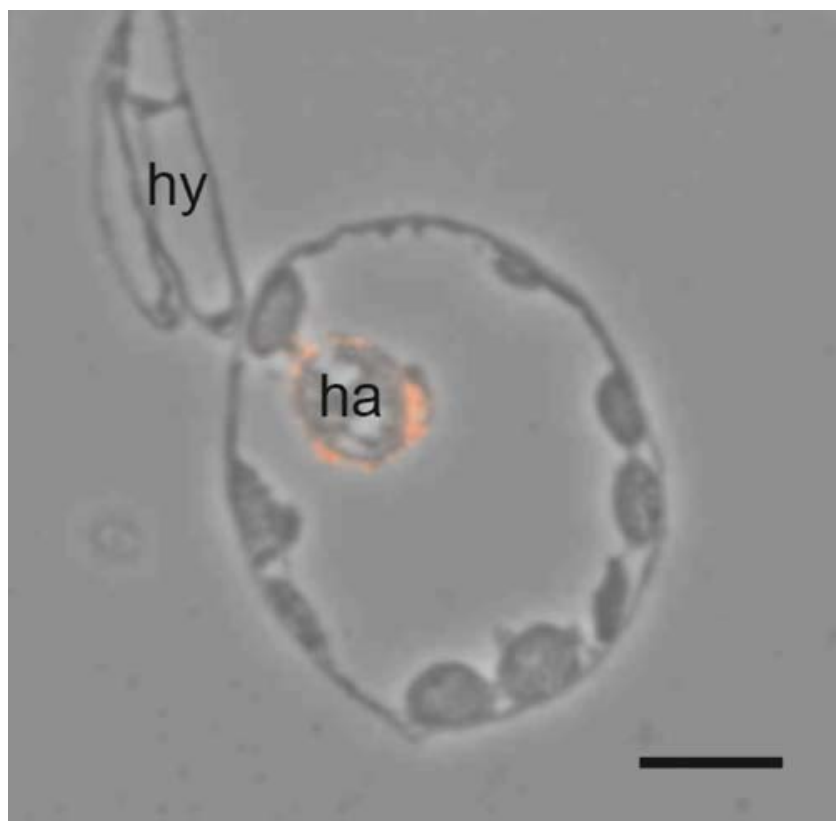

Fig. 5. Localization of the $U f-I N V 1$ gene product. Superimposed phase contrast and fluorescence images depicting a haustorium and an intercellular hypha. Labeling of INV1p with S698p resulted in strong fluorescence signals in the periphery of haustoria; ha, haustorium; hy, intercellular hypha. Bar $=10 \mu \mathrm{m}$.

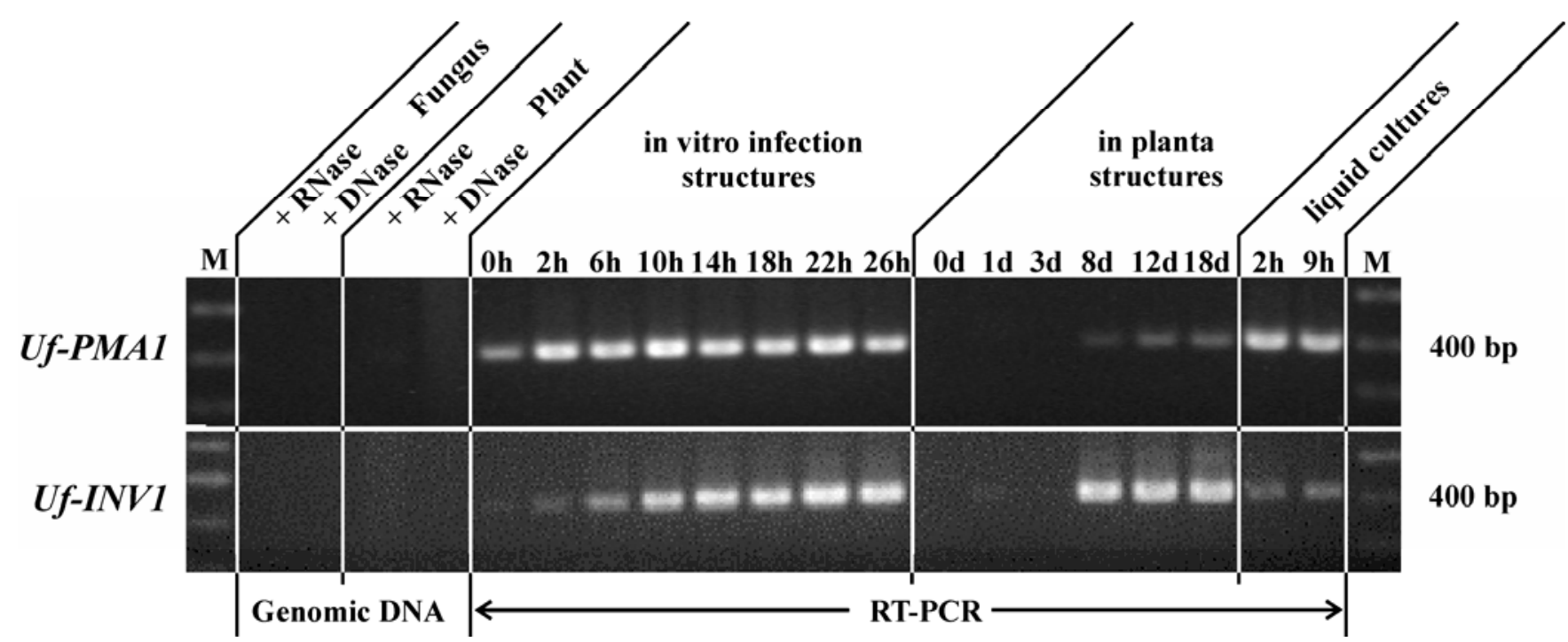

Fig. 4. Reverse-transcriptase polymerase chain reaction (RT-PCR) analysis of $U f$-INV1 expression. Agarose gels showing RT-PCR results for $U f$-PMA1 (constitutive control) and Uf-INV1. M: Molecular weight marker; genomic DNA: controls from Uromyces fabae (fungus) and Vicia faba (plant), samples received treatment with DNase or RNase as indicated. In vitro infection structures: grown for the indicated period after inoculation $(0$ h $=$ ungerminated spores); in planta structures: leaf samples various days after infection ( 0 days = noninfected leaves); liquid cultures: undifferentiated germ tubes 2 and 9 h old. All RNA samples received a DNase treatment. 


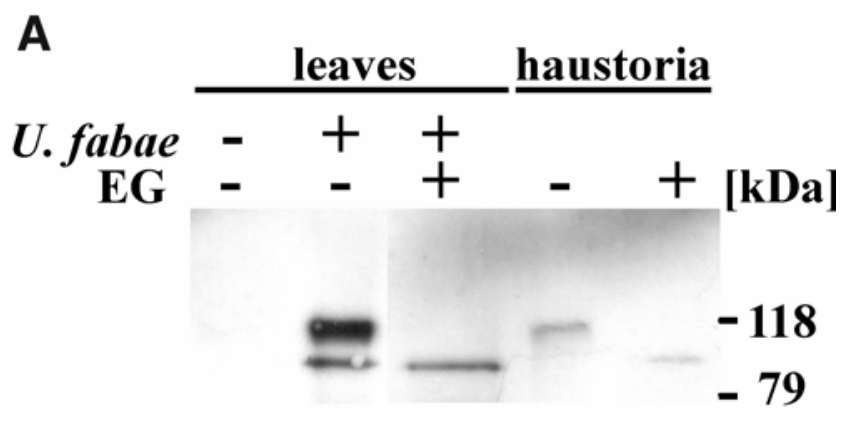

B

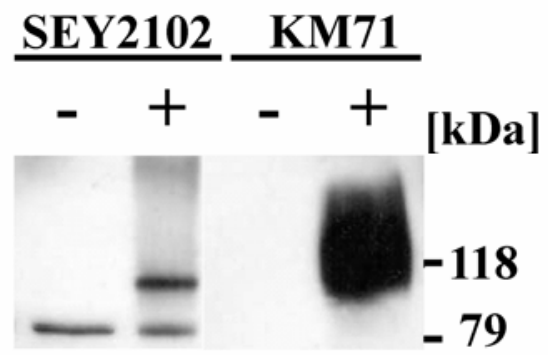

Fig. 6. Western blot analysis of INV1p in the native and the heterologous systems. A, Immunoblot analysis of leaf $(-=$ noninfected and $+=$ infected $)$ and haustorial samples after electrophoresis on a $10 \%$ sodium dodecyl sulfate-polyacrylamide gel electrophoresis (SDS-PAGE) gel. Samples were (EG+), or were not (EG-) treated with endoglycosidase $\mathrm{H}_{\mathrm{f}}$. B, Immunoblot analysis of TCA extracts of Saccharomyces cerevisiae SEY2102 cells and of the culture filtrate of Pichia pastoris KM71 after separation on a $10 \%$ SDS-PAGE gel; $-=$ vector transformants and $+=$ plasmids bearing INV1. Numbers on the right indicate the molecular weight standard.
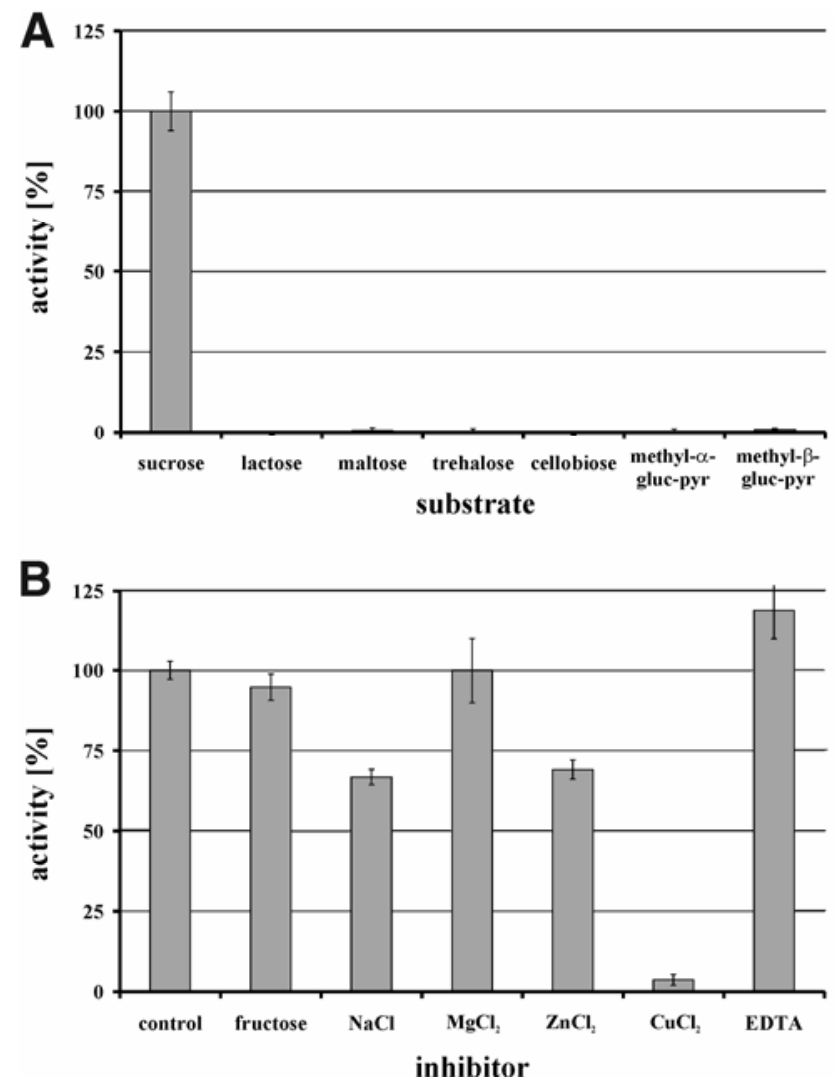

Fig. 7. A, Substrate specificity and B, inhibitors of INV1p*. A, Disaccharides and the glucopyranosides methyl- $\alpha$-glucopyranoside and methyl- $\beta$ glucopyranoside were tested at $100 \mathrm{mM}$. Activity with sucrose was set to $100 \%$. B, Inhibition was tested at $100 \mathrm{mM}$ sucrose. Fructose was added to $100 \mathrm{mM}$ and $\mathrm{NaCl}$ to $800 \mathrm{mM}$; all other salts and EDTA were added to a final concentration of $10 \mathrm{mM}$. Bars represent the means of triplicate experiments \pm standard error. sequence. This strategy resulted in a mature protein with the tetra peptide EAEA replacing the amino terminal serine residue (INV1p*). Using this construct, large quantities of the enzyme could be detected in cell-free culture filtrates (Fig. 6B). This soluble fraction was used to biochemically characterize the Uromyces fabae invertase.

\section{Biochemical characterization of INV1p*.}

INV1p* was stable in culture filtrate for several days when stored at $-20,4$, or $20^{\circ} \mathrm{C}$ (data not shown). Higher temperatures resulted in a rapid loss of enzyme activity. Addition of up to $20 \%$ glycerol, $200 \mathrm{mM} \mathrm{NaCl}$, or $50 \mathrm{mM}$ sucrose did not significantly alter INV1p* stability (data not shown). Sucrose was the only substance recognized as substrate (Fig. 7A). The reaction
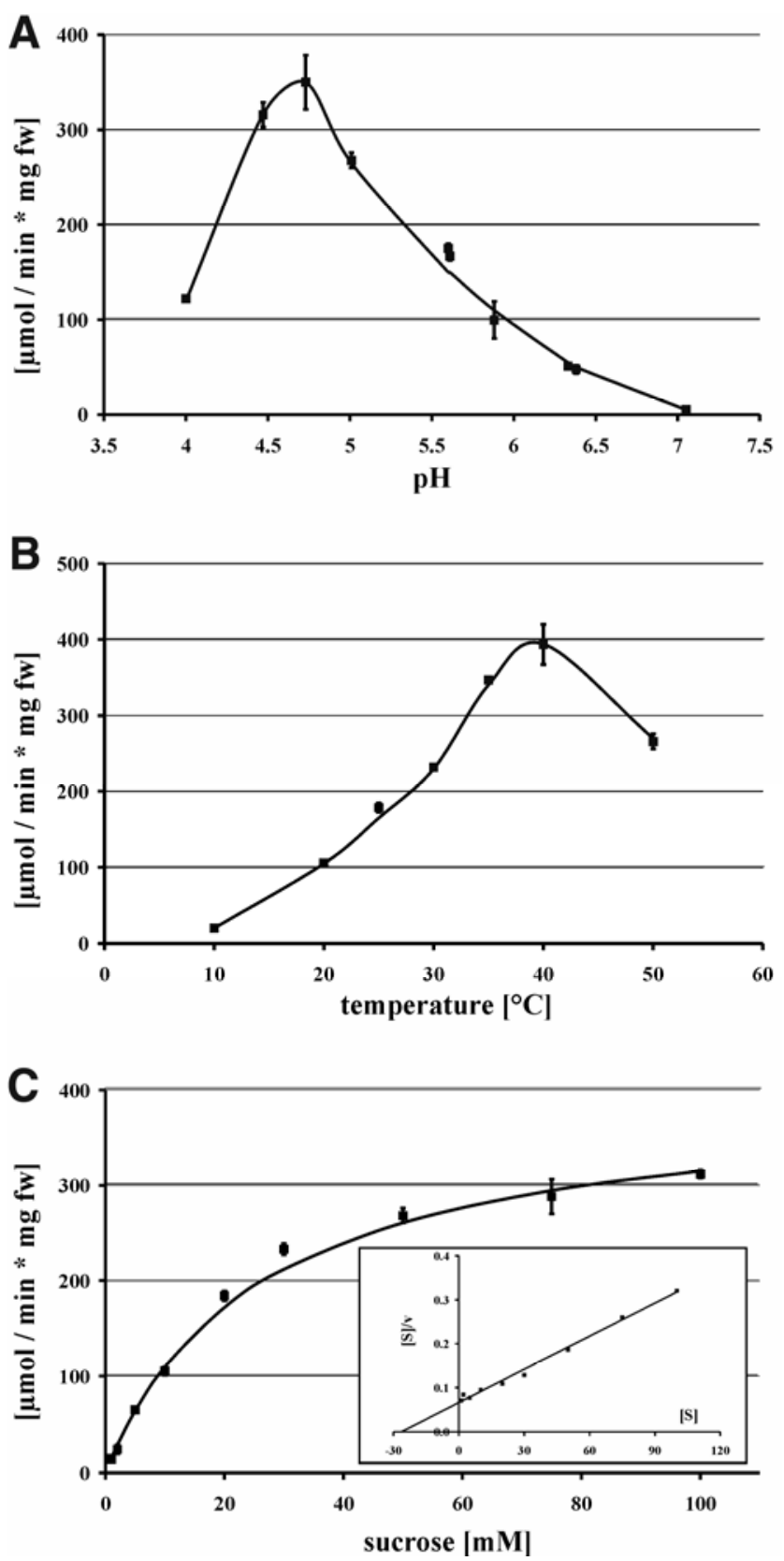

Fig. 8. A, $\mathrm{pH}$ and $\mathbf{B}$, temperature dependence and $\mathbf{C}$, Michelis-Menten plot for INV1p*. A, pH dependence of INV1p* was assayed using $100 \mathrm{mM}$ Na-acetate or $100 \mathrm{mM} \mathrm{Na-phosphate} \mathrm{buffer} \mathrm{at} 35^{\circ} \mathrm{C}$. B, Temperature dependence was monitored under standard conditions varying the initial incubation temperature. C, Michelis-Menten plot for INV1p*. The insert depicts the Hanes-Woolf transformation. Experiments were carried out in triplicate. Reported are the means \pm standard error. 
was not sensitive to fructose inhibition (Fig. 7B), but was negatively effected by high ionic strength $(0.8 \mathrm{M} \mathrm{NaCl})$. Divalent cations showed differential effects. Whereas magnesium did not affect the activity, zinc was slightly inhibitory and copper virtually abolished invertase activity (Fig. 7B). Addition of EDTA, on the other hand, resulted in a slight activity increase (Fig. 7B). The $\mathrm{pH}$ optimum was determined to be approximately $\mathrm{pH} 4.6$ (Fig. 8A). The temperature optimum was found to be slightly below $40^{\circ} \mathrm{C}$ (Fig. 8B). Analysis of the enzyme parameters under optimal conditions revealed a $\mathrm{K}_{\mathrm{M}}$ for sucrose of $27.1 \mathrm{mM}$ and a $\mathrm{V}_{\max }$ of $397 \mathrm{nmol} / \mathrm{min}$ per milligram of fresh weight (Fig. 8C).

\section{Plant invertases in the biotrophic interaction.}

In order to investigate the contribution of host invertases to sucrose cleavage in the biotrophic interaction of $U$. fabae with $V$. faba, we analyzed the expression pattern of the three known broad bean invertase genes using RT-PCR. Changes in transcription as a result of infection were examined in three plant organs: root, stem, and leaf. In healthy plants, expression of a vacuolar invertase (VCINVI) was highest in roots and gradually lower in stem and leaf samples (Fig. 9). In infected plants, expression of VCINV was greatly reduced in root samples and not detectable anymore in stems and leaves. CWINVI encoding a cell-wall-bound invertase isoform, that has been reported to be expressed during seed maturation (Weber et al. 1995), was not expressed in the vegetative organs analyzed, regardless of infection. In contrast, the second known $V$. faba gene encoding a cell-wall-bound invertase (CWINV2) was expressed in roots, but no other plant organ analyzed. Upon infection, expression in roots increased and, at the same time, expression also was detected in leaves. The results with VCINVI and
CWINV2 indicated that infection with the biotrophic leaf pathogen $U$. fabae altered the source/sink relationships throughout the host.

\section{DISCUSSION}

Characterization of a novel fungal invertase.

We have identified a new $\beta$-D-fructofuranoside fructohydrolase (EC 3.2.1.26) from the fungal plant pathogen $U$. fabae. This is the first characterization of an invertase from an obligate biotrophic plant parasite. With a molecular mass of approximately $84 \mathrm{kDa}$, the gene product, INV1p, is considerably larger than the average size of most other known invertases. However, the kinetic parameters determined for INV1p and the sequence homology found clearly identify the gene product as a true invertase. The presence of a predicted 25-aa signal sequence together with the detected $\mathrm{N}$-glycosylation indicates a secretion of the enzyme into the apoplast. This localization would indicate that INV1p should be classified as an acid invertase. The low $\mathrm{pH}$ optimum of 4.6 determined for the INV1pcatalyzed reaction supports this classification. However, Blast searches and sequence alignments identify INV1p as a member of a group of fungal invertases distinctly different from other secreted acid invertases. This group of invertases does not possess the complete $\beta$-fructosidase motif. In this group, the NDPN box seems to be reduced to NDP. The second motif, the WEC-V/P-D box discriminating between vacuolar and apoplastic acid invertases, is not present at all in these enzymes. Nevertheless, the absence of product inhibition and the sensitivity towards divalent cations supports a close relation to acid invertases (Roitsch and Gonzalez 2004). Unlike secreted inver-

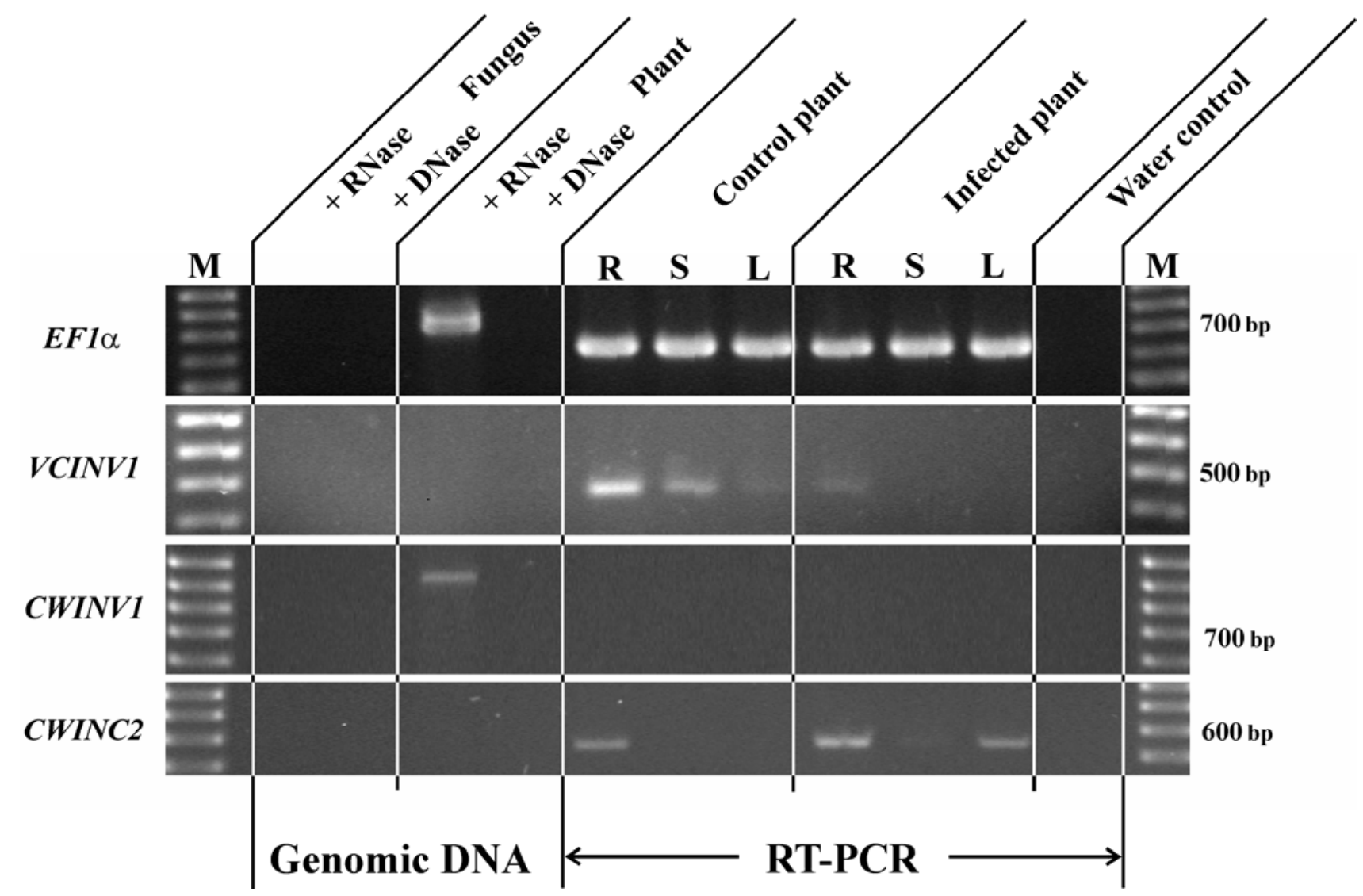

Fig. 9. Reverse-transcriptase polymerase chain reaction (RT-PCR) analysis of broad bean invertase expression. Agarose gels showing RT-PCR results for Vicia

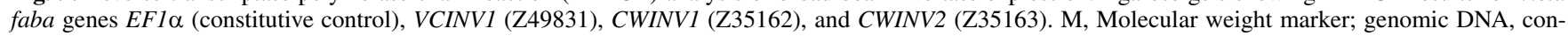
trols from Uromyces fabae (fungus) and V. faba (plant); samples received treatment with DNase or RNase as indicated. RT-PCR samples were obtained from healthy or infected plants at 12 days postinfection from the following organs: root (R), stem (S), and leaf (L). All RNA samples received a DNase treatment. 
tases in plants, INV1p does not seem to be ionically bound to the cell wall. The protein could be recovered from the growth medium after heterologous expression in $P$. pastoris, and it was localized in the soluble fraction after extraction from infected plants. The fact that it remained associated with SEY2102 cells (Fig. 6B) might be explained with S. cerevisiaespecific modifications to the polypeptide chain, as reported (Perez et al. 2001).

Our immunofluorescence data reveal a localization of INV1p in the extrahaustorial matrix only. On the other hand, the expression data from Northern analysis and RT-PCR experiments indicate an expression of the gene already in early infection structures, starting at approximately the time the fungus penetrates into the leaf. The discrepancy might be explained with different sensitivity levels of the detection methods or with the fact the INV1p seems to be a soluble protein which could, at least partly, be washed out during sample preparation. An alternative explanation could be that this gene is translationally controlled and, although message may be present, the protein may not be translated in structures other than haustoria.

\section{Possible roles for INV1p.}

Initially, we hypothesized that a fungal invertase should be present in the extrahaustorial matrix to provide the substrate for the $U$. fabae monosaccharide transporter, HXT1p (Voegele et al. 2001). Our localization of INV1p in the extrahaustorial matrix is consistent with this hypothesis. In this context, it is interesting to note that the apoplastic sucrose concentration in infected and noninfected $V$. faba leaves was determined to be just below $2 \mathrm{mM}$ (Voegele et al. 2005). HXT1p has MichaelisMenten constants of 0.3 and $1 \mathrm{mM}$ for D-glucose and D-fructose, respectively (Voegele et al. 2001). Assuming that the sucrose concentration in the extrahaustorial matrix is approximately the same as in the bulk apoplast, the sucrose-cleaving activity would become the rate-limiting step for providing hexoses for the fungus, if INV1p would be the only invertase involved. Unfortunately, there are no biochemical data available on the $V$. faba enzymes and, so far, our efforts to localize the $V$. faba enzymes have failed.

However, expression of INVI in early infection structures and intercellular hyphae cannot serve to provide substrate for HXT1p, because its expression is limited to haustoria (Voegele et al. 2001). An attractive explanation for the expression of INV1p in these structures stems from the role insoluble acid plant invertases have in the determination of the sink strength of a plant organ. Apoplastic hydrolysis of sucrose, either through insoluble plant acid invertases or the secreted fungal enzyme, would limit export of carbohydrates from the infected tissue via the phloem. Therefore, the fungus might use its invertase to condition the tissue for a conversion from source to sink. Consistent with this assumption are results from early studies on alteration in translocation patterns as a result of infection with a biotrophic fungus (Whipps and Lewis 1981). Livne and Daly (1966) reported a drop in export of fixed carbon from 50 to $2 \%$ upon infection of Phaseolus vulgaris leaves with $U$. phaseoli var. typica. Similar results were obtained for the pathosystem $V$. faba-U. fabae (Thrower and Thrower 1966). Therefore, our results support the idea that tissue infected with a biotrophic plant pathogen is converted from a source to a sink tissue, which has to compete with other naturally occurring sinks.

\section{Roles of plant invertases.}

The proposed conversion of source to sink tissue is supported by expression analysis of sucrose synthase (Wirsel et al. 2001). Under physiological conditions, the enzyme cleaves sucrose into D-fructose and UDP-glucose and, therefore, is important for the synthesis of UDP-glucose-derived storage compounds (Godt and Roitsch 1997). As a consequence, sucrose synthase activity also can be taken as a marker for sink strength (Sturm and Tang 1999). Upon infection of $V$. faba leaves with $U$. fabae, expression of $V f$-SUCS was downregulated in roots and stems but upregulated in infected leaves, underscoring the source sink transition. Therefore, we decided to analyze the expression pattern of the three known $V$. faba invertases. No expression could be found for CWINVI, which is consistent with earlier findings that this enzyme plays a role in early embryonic development (Weber et al. 1995). VCINV1, encoding for a soluble acid invertase, was downregulated in all tissues analyzed. Downregulation of vacuolar invertase is thought to decrease the amount of sucrose available for export through the phloem (Scholes et al. 1996). However, our previous studies did not indicate a concomitant significant rise in sucrose levels in infected leaves (Voegele et al. 2005). Therefore, it could be speculated that the expression of VCINVI is decreased because there is no sucrose deposited anymore in the vacuoles of the tissues tested. Most interesting were the alterations in the expression pattern of a second insoluble acid invertase, $C W I N V 2$. Upon infection, expression was detectable in leaves, which would be consistent with its role as a sink marker. However, infection with a leaf pathogen also altered $C W I N V 2$ expression in roots, indicating that the infection had systemic effects. At least in the infected tissue, these changes in gene expression do not seem to be due to regulatory effects caused, for example, by altered metabolite levels. In contrast to other systems analyzed (Chou et al. 2000; Tang et al. 1996), there seem to be no significant changes in the level of free hexoses or sucrose in the pathosystem $U$. fabae-V. faba (Voegele et al. 2005). It remains to be shown what causes, for example, the increase in expression of CWINV2.

Our results show that the biotrophic plant pathogen $U$. fabae does not rely solely on a host enzyme to satisfy its nutritional demands. Rather, it contributes its own invertase to the mobilization of hexoses. Alterations in the expression level of plant invertases indicate systemic effects of infection. Infected tissue is converted from a source to a sink, which then stands in competition with naturally occurring sinks.

\section{MATERIALS AND METHODS}

\section{Cultivation of plants and microorganisms.}

Cultivation of $V . f a b a \mathrm{cv}$. con Amore, inoculation with uredospores of $U$. fabae, germination of uredospores, and growth of in vitro-grown infection structures were carried out as described (Deising et al. 1991; Hahn and Mendgen 1997). Escherichia coli strains were grown in Luria-Bertani medium supplemented with the pertinent concentration of antibiotic (Miller 1972). S. cerevisiae strains were grown at $30^{\circ} \mathrm{C}$ in $\mathrm{SC}$ medium with $2 \%$ glucose or $2 \%$ sucrose as carbon source and drop-out mix lacking uracil (Sherman 1991). Pichia pastoris strains were grown at $30^{\circ} \mathrm{C}$ in $\mathrm{BMGY}$ or BMMY medium for induction (Pichia Expression Kit, Invitrogen, Carlsbad, CA, U.S.A.).

\section{Nucleic acid manipulations.}

Molecular procedures were performed according to standard protocols (Sambrook et al. 1989). S. cerevisiae transformation was carried out according to Elble (1992). P. pastoris was transformed by electroporation according to the manufacturer's instructions (Pichia Expression Kit). Plasmids were linearized with PmeI prior to transformation. Sequencing was done using the Big-Dye Terminator Cycle Sequencing Ready Reaction Mix (PE Applied Biosystems, Foster City, CA, U.S.A.) on an ABI 377 HT automated sequencer (GATC Biotech, Konstanz, Germany). Sequencing data were evaluated and analyzed using Chromas1.45 (Technelysium Pty. Ltd., Helensvale, Australia) and DNA-STAR (DNASTAR Inc., Madison, WI, U.S.A.). 
Nonradioactive hybridization was carried out according to the method of Engler-Blum and associates (1993). Genomic Southern and Northern hybridizations were done using homologous probes at hybridization temperatures between 65 and $68^{\circ} \mathrm{C}$. Signal detection was performed using anti-digoxigeninAP Fab fragments, CSPD (Roche Diagnostics GmbH, Mannheim, Germany) as substrate, and autoradiography.

\section{Phylogenetic analyses.}

Sequences that were similar to INV1p were obtained by database searches using the software BlastP. Matches and three sequences representing the currently annotated invertases of $V$. faba were used to create an alignment of 29 protein sequences with the software ClustalX. Phylogenetic analyses used two methods that are implemented in the software PAUP version $4.0 \mathrm{~b} 10$ (i.e., Neighbor Joining and Parsimony) (Swofford 2000). Both methods retrieved similar trees when using the BioNJ or heuristic search options, respectively, with other parameters set to default. Confidence of the resulting trees was estimated with 1,000 bootstrap replicates. Only the result of parsimony analysis in which the sequences of $V$. faba were used as outgroup to root the tree is shown (Fig. 1).

\section{RNA isolation, primer design, and RT-PCR.}

RNA isolation from spores, liquid cultures, in vitro-grown infection structures, and plant material was performed as described (Wirsel et al. 2001). Primers were designed according to the criteria outlined (Wirsel et al. 2001). All primers used for RT-PCR experiments are listed in Table 1. RT-PCR was carried out using the Titan One Tube RT-PCR kit (Roche $\mathrm{GmbH}$ ) as described (Wirsel et al. 2001).

\section{Plasmid constructions.}

For the generation of anti-INV1p-antibodies, two constructs were made. For the first construct, two internal EcoRI sites in the C-terminal half of the gene were used (nucleotide position 2,878 to 3,261 in the genomic sequence). A 311-bp fragment was excised from a partial $U f$-INVI-cDNA clone isolated from a haustorium-specific cDNA library (Hahn and Mendgen 1997) and ligated into EcoRI-digested vector pET32a(+) (Novagene, Madison, WI, U.S.A.). The resulting plasmid, pET32a(+)::INV1, encoded a His-tagged fusion protein consisting of 165 newly introduced amino acids at the N-terminus (including a 6xHis-cluster), amino acids 561 to 666 of INV1p, and another 17 aa including a second 6xHis-cluster. For the second construct a 1,126-bp fragment was amplified by PCR from uncloned haustorial cDNA by using primers INV-ab5, 5'GCTCCGTCGACC[841]CGTTACCGCTGATGACCGCC-3', and INV-ab6, 5'-GAGTGCGGCCGCTCA[2312]AAAATCCG CATTGGCTTTG-3', which introduced unique restriction sites (the introduced restriction sites are underlined and the numbers in brackets give the position of the preceding nucleotide in the genomic sequence). The PCR product was digested with SalI and NotI and ligated into SalI- and NotI-digested vector pET28a(+) (Novagene). The resulting plasmid, pET28a(+)::
$I N V n 2$, encoded a His-tagged fusion protein consisting of 41 newly introduced amino acids at the $\mathrm{N}$-terminus (including a 6xHis-cluster) and amino acids 33 to 271 of INV1p, followed by another 10 aa.

For expression of $U f-I N V 1$ in the invertase-deficient $S$. cerevisiae strain SEY2102 (Emr et al. 1983), a 2,338-bp fragment was amplified by nested PCR from uncloned haustorial cDNA by using primers INV17n (GAAGTCACAACCTGTGCG) and INV15n (GCAATATACTATATCATTCTCC) in the first step, and primers INV-not5 (5'-CTCGAGCGGCCGCC[717]GCTC CAGTGCCTGACG-3') and INV-ab2 (5'-GAGTGCGGCCGC CG[3,555]AAAGAAGAAAAGCAAAGAAATC- $3^{\prime}$ ), introducing two NotI restriction sites, in the nested step (the introduced restriction sites are underlined and the numbers in brackets give the position of the preceding nucleotide in the genomic sequence). The PCR product was digested with NotI and ligated into NotI-digested and dephosphorylated vector pBluescriptIIKS(+) (Alting-Mees and Short 1989). The NotI fragment was excised from plasmid pBluescriptIIKS(+)::INV1 and ligated into NotI-digested and dephosphorylated vector pDR195 (Rentsch et al. 1995). The resulting plasmid, pDR195::INV1, carried the complete open reading frame of $U f-I N V 1$, including native start and stop codons. Ampicillinresistant $E$. coli transformants were screened for the correct orientation of the insert using colony PCR with vector- and gene-specific primers.

For expression in $P$. pastoris, we replaced the INV1p secretion signal with the $\alpha$-factor signal peptide sequence provided on plasmid pPIC9 (Pichia Expression Kit). The large XhoINotI fragment was excised from plasmid pBluescriptIIKS(+):: INVI and ligated into XhoI- and NotI-digested pPIC9, creating plasmid pPIC9::INV1-ss. A 5' fragment of $U f$-INV1 was amplified by PCR from pBluescriptIIKS(+)::INV1 by using primers pp-INV1-xho, 5'-GTATCTCTCGAGAAAAGAGAGGCTGA AGCTT [825]TGCTTTATCAAGATTCCG-3' (the introduced XhoI restriction site is underlined and the number in brackets gives the position of the preceding nucleotide in the genomic sequence), and INV-ab6. The PCR product was digested with XhoI and the 202-bp XhoI fragment ligated into XhoI-digested and dephosphorylated plasmid pPIC9::INV1-ss. Ampicillinresistant $E$. coli transformants were screened for the correct orientation of the XhoI fragment using colony PCR with vector- and gene-specific primers. The resulting plasmid, pPIC9::INV1+ss, carried the complete sequence of mature INV1p from the predicted cleavage position (amino acid 26), preceded by the $\alpha$-factor signal peptide sequence encoded by pPIC9. Therefore, mature INV1p expressed in $P$. pastoris (INV1p*) has the amino terminal serine residue replaced by the four amino acids EAEA. Vector and plasmid were linearized with PmeI prior to transformation into P. pastoris KM71.

\section{Expression \\ of His-tagged fusion proteins and antibody generation. \\ Overexpression of the fusion proteins encoded by plasmids pET32a(+)::INV1 and pET28a(+)::INVn2 was done using $E$. coli}

Table 1. Primers used for reverse-transcriptase polymerase chain reaction (PCR)

\begin{tabular}{llll}
\hline Target & \multicolumn{1}{c}{ Conditions $^{\mathbf{a}}$} & Forward primer sequence $\left(\mathbf{5}^{\prime}\right.$ to $\left.\mathbf{3}^{\prime}\right)$ & \multicolumn{1}{c}{ Reverse primer sequence $\left(\mathbf{5}^{\prime}\right.$ to $\left.\mathbf{3}^{\prime}\right)$} \\
\hline$U f-P M A 1$ & Cyc: 30, ann: $56^{\circ} \mathrm{C}$ & ATTTGTGTGCAATGACTGG & GATGGCGTATGTGAAAATCT \\
$U f-I N V 1$ & Syn: $50^{\circ} \mathrm{C}$, cyc: 25 & CCCATGGCAGTCTTTGAA & TCAAACCGGTAGGAGCAAAAGTC \\
$E F 1 a$ & Standard & TTAAGGCTGAGCGTGAAAGAGG & CCTCTTTTGATCCGGATGGTATGG \\
$V C I N V 1$ & Standard & CTTCCCGTCGTGGTGCCTTAG & AACCCCGCCTCGAACTTTTGA \\
$C W I N V 1$ & Ann: $55^{\circ} \mathrm{C}$, syn: $50^{\circ} \mathrm{C}$ & TGGTTCGGCAAGGATGGACAC & ATTCATTAACCCAACCAAGCAAA \\
$C W I N V 2$ & Ann: $55^{\circ} \mathrm{C}$, syn: $50^{\circ} \mathrm{C}$ & TTTCTAAGGGAATGGATCAAGTCAC & \\
\hline
\end{tabular}

${ }^{a}$ Changes from standard conditions were as indicated: 'ann' refers to the final annealing temperature of the first PCR block and all cycles of the second PCR

block, 'syn' refers to the first-strand synthesis step temperature, and 'cyc' refers to the number of cycles of the second PCR block. 
BL21(DE3) and induction with IPTG (Studier and Moffat 1986). Purification of the fusion proteins was performed using immobilized metal ion affinity chromatography under denaturing conditions according to the manufacturer's protocol (The QIAexpressionist, Qiagen, Hilden, Germany). Antibodies were obtained by repeated biweekly injection of a female New Zealand White rabbit with $500 \mu \mathrm{g}$ of purified fusion protein together with Freund's Adjuvant (S698 for the pET32a(+):: INV1 encoded antigen and S755 for the pET28a(+)::INVn2 encoded fusion protein). Sera were purified in a two-step procedure as described (Voegele et al. 2001). Proteins used for negative adsorption were encoded by the vector pET32a $(+)$ for pET32a(+)::INV1 and pET28a(+)::CWINV24 for pET28a(+):: $I N V n 2$. pET28a(+)::CWINV24 encodes another fusion protein identical to the $I N V \mathrm{n} 2$ fusion protein with respect to the newly introduced amino acids, except for four.

\section{SDS-PAGE and immunoblot analyses.}

Protein preparations were separated on 7.5 or $10 \%$ SDSPAGE (sodium dodecyl sulfate-polyacrylamide gel electrophoresis) gels (Laemmli 1970). Immunoblot analysis was conducted as described previously (Sohn et al. 2000). As primary antibody, purified rabbit anti-invertase sera (S698p or S755p) were used. Visualization was performed with peroxidase-coupled goat anti-rabbit secondary antibody (Sigma-Aldrich Chemie GmbH, Mannheim, Germany) and ECL Western Blot Detection Reagent (Amersham Bioscience, Freiburg, Germany).

Proteins used for immunoblot analysis were obtained according to Haerter and Voegele (2004) with the following modifications. Protein was precipitated from 48-h-old S. cerevisiae SEY2102 pDR195::INV1 cultures by treatment of the cells with $40 \%$ TCA. Supernatant of $P$. pastoris KM71 pPIC9::INV1+ss cultures (24 h old) was used without further treatment. For deglycosylation, protein samples were denatured at $95^{\circ} \mathrm{C}$ for $10 \mathrm{~min}$. Samples then were incubated with endoglycosidase $\mathrm{H}_{\mathrm{f}}$ (NEB, Beverly, MA, U.S.A.) at $100 \mathrm{U} / \mu \mathrm{l}$ in 5 $\mathrm{mM}$ sodium citrate at $\mathrm{pH} 5.5$ and $37^{\circ} \mathrm{C}$ for $3 \mathrm{~h}$.

\section{Enzyme assays.}

INV1p* was stored in culture filtrate of $P$. pastoris KM71 pPIC9::INV1+ss cultures at $4^{\circ} \mathrm{C}$. The standard invertase assay consisted of $100 \mathrm{mM} \mathrm{Na}$-acetate, $\mathrm{pH} 4.6$, and $100 \mathrm{mM}$ sucrose. Assays were incubated at $35^{\circ} \mathrm{C}$ in a time-dependent manner. Reactions were stopped by boiling for $15 \mathrm{~min}$, followed by centrifugation at $16,000 \times g$. Aliquots of the invertase assays were analyzed for their glucose content using the D-glucose UV-test (R-Biopharm AG, Darmstadt, Germany) scaled to microtiter plate volume according to the manufacturer's instructions. Enzyme activity was reported as micromol substrate converted per minute per milligram of cellular fresh weight. The temperature optimum was determined by varying the incubation temperature at constant $\mathrm{pH}$. $\mathrm{pH}$-dependence was analyzed using $\mathrm{Na}$-acetate and phosphate buffers at the indicated $\mathrm{pH}$ values at $35^{\circ} \mathrm{C}$. Kinetics were recorded by varying the sucrose concentration and inhibitor studies were done by adding the test substance to the standard assay at the concentrations indicated. All assays were done in triplicate and repeated at least twice.

Protein concentrations were determined by the Bradford method (Bradford 1976) using the BioRad protein assay dye (BioRad, Hercules, CA, U.S.A.) following the microassay procedure with dilutions of bovine serum albumin (BSA) as standard.

\section{Immunocytochemistry.}

Microscopic analyses were performed as described (Voegele et al. 2001).

\section{ACKNOWLEDGMENTS}

This work was supported by a grant provided by the Deutsche Forschungsgemeinschaft to K. Mendgen and R. T. Voegele (Me 523/24-1). We are grateful to H. Vahlenkamp and A. Schmid for expert technical assistance, and we would like to thank M. Hahn for critically reading the manuscript.

\section{LITERATURE CITED}

Alting-Mees, M. A., and Short, J. M. 1989. pBluescript II: Gene mapping vectors. Nucleic Acids Res. 17:9494.

Bendtsen, J. D., Nielsen, H., von Heijne, G., and Brunak, S. 2004. Improved prediction of signal peptides: SignalP 3.0. J. Mol. Biol. 340:783-795.

Benhamou, N., Grenier, J., and Chrispeels, M. J. 1991. Accumulation of beta-fructosidase in the cell walls of tomato roots following infection by a fungal wilt pathogen. Plant Physiol. 97:739-750.

Billett, E. E., Billett, M. A., and Burnett, J. H. 1977. Stimulation of maize invertase activity following infection by Ustilago maydis. Phytochemistry 16:1163-1166.

Boddy, L. M., Berges, T., Barreau, C., Vainstein, M. H., Dobson, M. J., Ballance, D. J., and Peberdy, J. F. 1993. Purification and characterisation of an Aspergillus niger invertase and its DNA sequence. Curr. Genet. 24:60-66.

Bradford, M. M. 1976. A rapid and sensitive method for the quantitation of microgram quantities of protein utilizing the principle of protein-dye binding. Anal. Biochem. 72:248-254.

Callow, J. A., Long, D. E., and Lithgow, E. D. 1980. Multiple molecular forms of invertase in maize smut Ustilago maydis infections. Physiol. Plant Pathol. 16:93-107.

Chou, H. M., Bundock, N., Rolfe, S. A., and Scholes, J. D. 2000. Infection of Arabidopsis thaliana leaves with Albugo candida (white blister rust) causes a reprogramming of host metabolism. Mol. Plant Pathol. 1:99113.

Deising, H., Jungblut, P. R., and Mendgen, K. 1991. Differentiationrelated proteins of the broad bean rust fungus Uromyces viciae-fabae, as revealed by high resolution two-dimensional polyacrylamide gel electrophoresis. Arch. Microbiol. 155:191-198.

Elble, R. 1992. A simple and efficient procedure for transformation of yeasts. Biotechnology 13:18-20.

Emr, S. D., Schekman, R., Flessel, M. C., and Thorner, J. 1983. An $M F \alpha 1-$ SUC2 ( $\alpha$-factor-invertase) gene fusion for study of protein localization and gene expression in yeast. Proc. Natl. Acad. Sci. U.S.A. 80:70807084 .

Engler-Blum, G., Meier, M., Frank, J., and Müller, G. A. 1993. Reduction of background problems in nonradioactive Northern and Southern blot analyses enables higher sensitivity than ${ }^{32} \mathrm{P}$-based hybridizations. Anal. Biochem. 210:235-244.

Eschrich, W. 1989. Phloem unloading of photoassimilates. Pages 206-263 in: Transport of photoassimilates. D. A. Baker and J. A. Milburn, eds. Longman Scientific \& Technical, Harlow, UK.

Fotopoulos, V., Gilbert, M. J., Pittman, J. K., Marvier, A. C., Buchanan, A. J., Sauer, N., Hall, J. L., and Williams, L. E. 2003. The monosaccharide transporter gene, AtSTP4, and the cell-wall invertase, At $\beta$ fruct1, are induced in Arabidopsis during infection with the fungal biotroph Erysiphe cichoracearum. Plant Physiol. 132:821-829.

Godt, D. E., and Roitsch, T. 1997. Regulation and tissue-specific distribution of mRNAs for three extracellular invertase isoenzymes of tomato suggests an important function in establishing and maintaining sink metabolism. Plant Physiol. 115:273-282.

Goetz, M., and Roitsch, T. 1999. The different $\mathrm{pH}$ optima and substrate specificities of extracellular and vacuolar invertases from plants are determined by a single amino- acid substitution. Plant J. 20:707-711.

Goetz, M., and Roitsch, T. 2000. Identification of amino acids essential for enzymatic activity of plant invertases. J. Plant Physiol. 157:581-585.

Haerter, A. C., and Voegele, R. T. 2004. A novel $\beta$-glucosidase in Uromyces fabae: Feast or fight? Curr. Genet. 45:96-103.

Hahn, M., and Mendgen, K. 1997. Characterization of in planta-induced rust genes isolated from a haustorium-specific cDNA library. Mol. Plant-Microbe Interact. 10:427-437.

Heisterüber, D., Schulte, P., and Moerschbacher, B. M. 1994. Soluble carbohydrates and invertase activity in stem rust-infected, resistant and susceptible near-isogenic wheat leaves. Physiol. Mol. Plant Pathol. 45:111-123.

Heyer, A. G., Raap, M., Schroeer, B., Marty, B., and Willmitzer, L. 2004. Cell wall invertase expression at the apical meristem alters floral, architectural, and reproductive traits in Arabidopsis thaliana. Plant J. 39:161-169.

Heyer, A. G., and Wendenburg, R. 2001. Gene cloning and functional char- 
acterization by heterologous expression of the fructosyltransferase of Aspergillus sydowi IAM 2544. Appl. Environ. Microbiol. 67:363-370.

Krishnan, H. B., and Pueppke, S. G. 1988. Invertases from rust-infected wheat leaves. J. Plant Physiol. 133:336-339.

Laemmli, U. K. 1970. Cleavage of structural proteins during the assembly of the head of bacteriophage T4. Nature (Lond.) 227:680-685.

Livne, A., and Daly, J. M. 1966. Translocation in healthy and rust-affected beans. Phytopathology 56:170-175.

Miller, J. H. 1972. Experiments in Molecular Genetics. Cold Spring Harbor Laboratory Press, Cold Spring Harbor, NY, U.S.A.

Myrbäck, K. 1960. Invertases. Pages 379-396 in: The Enzymes. P. Boyer, H. Lardy, and K. Myrbäck, eds. Academic Press, New York.

Neumann, N. P., and Lampen, J. O. 1967. Purification and properties of yeast invertase. Biochemistry 6:468-475.

Perez, J. A., Rodriguez, J., Ruiz, T., and Rodriguez, L. 2001. Expression of Pichia anomala INV1 gene in Saccharomyces cerevisiae results in two different active forms of hypoglycosylated invertase. Arch. Microbiol. 175:189-197.

Ramloch-Lorenz, K., Knudsen, S., and Sturm, A. 1993. Molecular characterization of the gene for carrot cell wall beta-fructosidase. Plant J. 4:545-554.

Rentsch, D., Laloi, M., Rouhara, I., Schmelzer, E., Delrot, S., and Frommer, W. B. 1995. NTRI encodes a high affinity oligopeptide transporter in Arabidopsis. FEBS (Fed. Eur. Biol. Soc.) Lett. 370:264-268.

Roitsch, T., and Gonzalez, M. C. 2004. Function and regulation of plant invertases: Sweet sensations. Trends Plant Sci. 9:606-613.

Ruffner, H. P., Geissmann, M., and Rast, D. M. 1992. Plant and fungal invertases in grape berries infected with Botrytis cinerea. Physiol. Mol. Plant Pathol. 40:181-189.

Ruiz, E., and Ruffner, H. P. 2002. Immunodetection of Botrytis-specific invertase in infected grapes. J. Phytopathol. 150:76-85.

Sambrook, J., Fritsch, E. F., and Maniatis, T. 1989. Molecular Cloning: A Laboratory Manual. Cold Spring Harbor Laboratory Press, Cold Spring Harbor, NY, U.S.A.

Scholes, J., Bundock, N., Wilde, R., and Rolfe, S. 1996. The impact of reduced vacuolar invertase activity on the photosynthetic and carbohydrate metabolism of tomato. Planta 200:265-272.

Sherman, F. 1991. Getting started with yeast. Pages 3-21 in: Methods in Enzymology: Guide to Yeast Genetics and Molecular Biology. C. Guthrie and G. R. Fink, eds. Academic Press, San Diego, CA, U.S.A

Sohn, J., Voegele, R. T., Mendgen, K., and Hahn, M. 2000. High level activation of vitamin $\mathrm{B} 1$ biosynthesis genes in haustoria of the rust fungus Uromyces fabae. Mol. Plant-Microbe Interact. 13:629-636.

Studier, F. W., and Moffat, B. A. 1986. Use of bacteriophage T7 RNA polymerase to direct selective high-level expression of cloned genes. J. Mol. Biol. 189:113-130.

Sturm, A. 1999. Invertases. Primary structures, functions, and roles in plant development and sucrose partitioning. Plant Physiol. 121:1-8.

Sturm, A., and Tang, G. Q. 1999. The sucrose-cleaving enzymes of plants are crucial for development, growth and carbon partitioning. Trends Plant Sci. 4:401-407.
Swofford, D. L. 2000. Phylogenetic Analysis Using Parsimony (* and Other Methods) Version 4. Sinauer Associates, Sunderland, MA, U.S.A.

Tang, X., Rolfe, S. A., and Scholes, J. D. 1996. The effect of Albugo candida (white blister rust) on the photosynthetic and carbohydrate metabolism of leaves of Arabidopsis thaliana. Plant Cell Environ. 19:967-975.

Thrower, L. B., and Thrower, S. L. 1966. The effect of infection with Uromyces fabae on translocation in Broad Bean. Phytopathol. Z. 57:267276.

Tymowska-Lalanne, Z., and Kreis, M. 1998. The plant invertases: Physiology, biochemistry, and molecular biology. Adv. Bot. Res. 28:71-117.

Voegele, R. T., Hahn, M., Lohaus, G., Link, T., Heiser, I., and Mendgen, K. 2005. Possible roles for mannitol and Mannitol Dehydrogenase in the biotrophic plant pathogen Uromyces fabae. Plant Physiol. 137:190198.

Voegele, R. T., Struck, C., Hahn, M., and Mendgen, K. 2001. The role of haustoria in sugar supply during infection of broad bean by the rust fungus Uromyces fabae. Proc. Natl. Acad. Sci. U.S.A. 98:8133-8138.

Weber, H., Borisjuk, L., Heim, U., Buchner, P., and Wobus, U. 1995. Seed coat-associated invertases of fava bean control both unloading and storage functions: Cloning of cDNAs and cell type-specific expression. Plant Cell 7:1835-1846.

Weber, H., and Roitsch, T. 2000. Invertases and life beyond sucrose cleavage. Trends Plant Sci. 5:47-48.

Weschke, W., Panitz, R., Gubatz, S., Wang, Q., Radchuk, R., Weber, H., and Wobus, U. 2003. The role of invertases and hexose transporters in controlling sugar ratios in maternal and filial tissues of barley caryopses during early development. Plant J. 33:395-411.

Whipps, J. M., and Lewis, D. H. 1981. Patterns of translocation, storage and interconversion of carbohydrates. Pages 47-83 in: Effects of Disease on the Physiology of the Growing Plant. P. G. Ayers, ed, Cambridge University Press, Cambridge.

Williams, A. M., Maclean, D. J., and Scott, K. J. 1984. Cellular location and properties of invertase in mycelium of Puccinia graminis. New Phytol. 98:451-463.

Wirsel, S. G., Voegele, R. T., and Mendgen, K. W. 2001. Differential regulation of gene expression in the obligate biotrophic interaction of Uromyces fabae with its host Vicia faba. Mol. Plant-Microbe Interact. 14:1319-1326.

Wright, D. P., Baldwin, B. C., Shephard, M. C., and Scholes, J. D. 1995 Source-sink relationships in wheat leaves infected with powdery mildew. I. Alterations in carbohydrate metabolism. Physiol. Mol. Plant Pathol. 47:237-253.

Yanai, K., Nakane, A., Kawate, A., and Hirayama, M. 2001. Molecular cloning and characterization of the fructooligosaccharide-producing beta-fructofuranosidase gene from Aspergillus niger ATCC 20611. Biosci. Biotechnol. Biochem. 65:766-773.

\section{AUTHOR-RECOMMENDED INTERNET RESOURCE}

BRENDA database: http://brenda.bc.uni-koeln.de/ 